\title{
Mechanistic Pathways of ATP Sensitive Potassium Channels Referring to Cardio-Protective Effects and Cellular Functions
}

\author{
Authors \\ Vishal Kumar Vishwakarma', Prabhat Kumar Upadhyay², Hridaya Shanker Chaurasiya', Ritesh Kumar Srivasatav³, \\ Tarique Mahmood Ansari ${ }^{4}$, Vivek Srivastava ${ }^{1}$
}

\section{Affiliations}

1 Department of Pharmacology, R.R.S College of Pharmacy, Amethi, Uttar Pradesh, India

2 Institute of Pharmaceutical Research, GLA University, Mathura, Uttar Pradesh, India

3 Faculty of Pharmacy, Kamla Nehru Institute of Management and Technology, Sultanpur, India

4 Department of Pharmacy, Integral University, Lucknow, Uttar Pradesh, India

\section{Key words}

potassium channel, ischemic preconditioning,

cardio-protection, skeletal muscle

\section{received 04.10 .2018}

accepted 23.11.2018

\section{Bibliography}

DOI https://doi.org/10.1055/a-0806-7207

Published online: 4.1.2019

Drug Res 2019; 69: 365-373

(C) Georg Thieme Verlag KG Stuttgart · New York

ISSN 2194-9379

\section{Correspondence}

Vishal Kumar Vishwakarma

Department of Pharmacology

R.R.S College of Pharmacy

Amethi

227405 Uttar Pradesh

India

Tel.: + 91/988/9654 167, Fax: + 91/5662/241687

vishal049uip@gmail.com

\begin{abstract}
A study of potassium channels correlates the fundamentals of mechanistic pathways and various physiological functions. The knowledge of these pathways provides the background, how to determine unit cell functions and to affect cardio protection. ATP sensitive potassium channels adjust excitability of membrane and functions as per metabolic status of cell. A lot of energy consumption primarily occurred in skeletal muscles which also express high number of potassium channels. The increase in calcium release and high heat production is occurred due to loss of potassium channels. Such type of mediations determines metabolic changes and energy required in the dissipation. IPC reduces infarct size in anesthetized mice. In ischemic-reperfusion, pressure in left ventricle was watched while contractile power recovery did not happen. It was seen that elements of intact potassium channel are fundamental for Ischemic preconditioning (IPC). If more prominent is enactment of potassium channels and their cardiologic effects create high heart rate. All the more as of late, it has been suggested that mitochondrial ATP sensitive potassium channels are critical as closing stage effectors which trigger IPC as opposed to sarcolemmal potassium channels. Nevertheless, the importance of the potassium channels reconsidered in cardio-protection in present findings. These discoveries recommend that potassium channels in the adjusting ischemic-reperfusion damage in mice. The heart rate of the mouse occurred during ischemia; enhance watchful extrapolation applied to larger warm blooded animals.
\end{abstract}

\section{Introduction}

ATP-sensitive potassium ( $\mathrm{K}_{\text {ATP }}$ ) channels have the bend nature to alter membrane properties and control the cell metabolic status [1]. $K_{\text {ATP }}$ channels are generally spread in various tissues including cerebrum, pancreas, heart and skeletal muscle.

Different types of these channels add to particular properties of cells and tissues. Skeletal muscle $\mathrm{K}_{\text {ATP }}$ channels are on a very basic level bound through physical relationship in 4 potassium channel
[2]. A potassium channel like Kir 6.1, a weak significant modifier, with 4 working sulfonylurea receptor subunits, SUR2A, and incredibly less articulation of SUR1 and subunits of Kir6.1 [3]. The channel mediated metabolic status occurs via path of the $\mathrm{K}^{+}$pore ATP sensitivity by subunit of SUR, which play a role in activation of channel by Mg-ADP; potassium channel openers and affected by sulfonylurea drugs. Skeletal muscles and heart are highly significant sites for physical activity where $\mathrm{K}_{\text {ATP }}$ are found in high frequency [4]. 
In the heart, direct opening of $\mathrm{K}_{\text {ATP }}$ channel happens in light of various burdens related with either decreased vitality accessibility, for example, hypoxia or ischemia [5], or expanded vitality utilization including expanding heart rate inside the typical, physiological range. The resultant cell potassium efflux advances activity potential shortening, hence restricting the drive for calcium deluge and calcium instigated calcium discharge. This spares cell vitality that would some way or another be used for calcium homeostasis and choking [6].

An abbreviated activity potential range (AP) furthermore achieves a more broadened diastolic interval, essential for vitality hold renewal. Along these lines, a fundamental bit of ventricular $\mathrm{K}_{\text {ATP }}$ channels is alteration of the AP to streamline cardiovascular limit over a far reaching extent of workloads while avoid fatigue of cell metabolic assets that provoke damage or brokenness [7].

\section{Involvement of $\mathrm{K}_{\mathrm{ATP}}$ Channel in Ischemic Preconditioning}

IPC is a process by which compact irregular conditions of ischemia impenetrably protect the myocardium against different insults of ischemia, leading to decline of infarct size. At first it was recom-

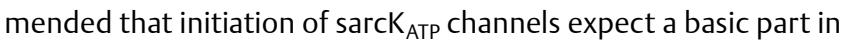
IPC. In fact, a number of examinations have shown that IPC was replicated by potassium channel openers [8] and lessening through sulfonylurea $\mathrm{K}_{\text {ATP }}$ channel blocker glibenclamide [9].

Grover et al. (1995) [10] proposed that it was not connected between APD shortening \& cromakalim associated cardioprotection in dogs. The class III threatening to arrhythmic medications Dofetilide and Terikalant which was not targets, each ineffectively to segregate the cardio-protective purpose behind IPC [11]. A later, elective proposition guesses that mitochondria port another kind of $\mathrm{K}_{\text {ATP }}$ channel, and union of mito- $\mathrm{K}_{\text {ATP }}$ channels comparing with sarc $K_{\text {ATP }}$ channels, show cardio-protection comprising IPC. Likewise, it has been revealed that diazoxide and 5-HD are by and large particular activators and blockers of mito $\mathrm{K}_{\text {ATP }}$ Occupy in cardio myocytes, exclusively, at littlest under non ischemic situation [12]. It was at first hypothesized by Noma et al., that incitation of sarcK ATP $_{\text {PT }}$ channels act as an endogenous guard of heart structure. Movement potential shortening because of sarcK ATP $_{\text {channel establishment is }}$ required to decrease perfect open door for $\mathrm{Ca}^{2+}$ joining by methods involving L-type channels of $\mathrm{Ca}^{2+}$ and to extend perfect open door for $\mathrm{Ca}^{2+}$ removal.

Without any doubt, untreated KO hearts and WT hearts with HMR1098-treatment extended for a period for the discontinuance of of pressure in the midst of ischemia contrasting and untreated WT hearts, those are by and large credited to nonappearance of dampened cardiovascular contractions as a result of movement potential shortening. In this condition, it is noteworthy that quality movement of Kir-6.2 and SUR - 2 A to COS-7 cells can endure cost of the cytoprotection against $\mathrm{Ca}^{2+}$ over-load promoted by hypoxia/reperfusion [13].

The outcomes of movement were not delivered in the refined cells, hyperpolarization of cell layer coming to completion in the starting of sarc- $K_{\text {ATP }}$ channel may accept a basic part in the cyto-protection. It was proposed by various researchers that mito $K_{\text {ATP }}$ channels may depolarize the mitochondrial film, as needs be hindering mitochondrial $\mathrm{Ca}^{2+}[14]$. If narrowing of mitochondrial $\mathrm{Ca}^{2+}$ overload is one of fundamental instruments of mito- $\mathrm{K}_{\text {ATP }}$ channel- interceded cardio affirmation, intracellular $\mathrm{Ca}^{2+}$ in the ischemia in $\mathrm{KO}$ heart cells was found too much for mitochondria damage.

Activation of sarc- $\mathrm{K}_{\text {ATP }}$ channel has moreover been gave off an impression of being fundamental for cell security in various tissues and furthermore the cerebrum [15] and skeletal muscle [16]. Different examinations have exhibited that inception of mito- $K_{\text {ATP }}$ channel is for appropriate on time and put off preconditioning in animal [17] and furthermore human myocardium [18]. Right when non beating myocardial plan are used for preconditioning tests, mito-K $K_{\text {ATP }}$ channels may accept an all the more overpowering part in the cardioprotection. The limitation of development by sulfonylureas and so forth, for example, Dofetilide and Terikalant should not be done under crazy ischemic conditions.

Certainly both sarcK $\mathrm{ATP}_{\text {AT }}$ and mitoK $\mathrm{K}_{\text {ATP }}$ channels are responsible for the cardio-protection, forgeting about way that several differentiations in their qualities among animal species and exploratory conditions. It has been questionable that sarc- $\mathrm{K}_{\text {ATP }}$ or mitoK $\mathrm{K}_{\text {ATP }}$ match some regular highlights in IPC [19]. The present examination has

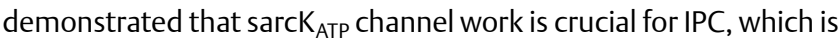
a high-heart-rate creature assortment in any way in mouse. It was proposed that digoxin, limits sarck $\mathrm{ATP}_{\text {C }}$ channel and conveys intracellular $\mathrm{Ca}^{2+}$ over-load by $\mathrm{Na}^{+} \mathrm{K}^{+}$ATPase block, repealed IPC in vivo hearts of rabbit [20]. In all terms, it has been represented to that both of mito- $K_{\text {ATP }}$ and sarcK $\mathrm{K}_{\text {ATP }}$ channels in canine heart, expect an essential limit of infarct estimated after IPC mechanism [21] and in erratic pain relieving [22]. The ischemic daamge is higher at standard in KO hearts than in WT hearts may destabilize IPC conventions in the 2 different ways. The Kir6.2-lacking mice push the criticalness of sarck $_{\text {ATP }}$ that involves in cardio-security.

\section{Mitochondrial ATP-sensitive $\mathrm{K}^{+}$Channel and Rodent Cardiomyocytes}

The presence of Kir6. 1 protein in coronary supply routes of rodents and cardiomyocytes was predictable with the far reaching assignment of Kir6.1 mRNA of rat heart [23] and in the smooth muscle of veins [24]. The subtypes of Kir6. 1 in mitochondria which were considered to results in detached part of mitochondria and myocytic ventricles observed by an examination and localized with MitoFluor red, a mitochondrial pointer [25]. The repression of Kir6.2 in ER as well as cell layer in the cardiomyocytes of rat was related to results got in electron microscopy having neurons and glial cells of cerebrum of rat [26]. The Kir6.2 proteins on ER address the site before the course of action in reasonable octamers associated with sulphonylurea receptors on cell layer [27]. A quality trade procedure did not represent in which mitochondria posess Kir6. 1 or Kir6.2 proteins [28]. Additionally, an immunoblot examination without Kir6.1 or Kir6.2 proteins in mitochondria [29].

At that point, it has been kept up both Kir6.1 and Kir6.2 channels were not the parts of mitochondria. The proteins, Kir6.1 and Kir6. 2 were available in mitochondria seen by immunoblot examination of mitochondrial parts following electron microscopy [30] and in separated ventricular myocytes in rats utilizing immuno-cytometry. Kuniyasu et al. (2003) [29] utilized approaches to change their antibodies and show specificities by immunoblot examination 
are relatively same as Singh et al. (2003) [25] utilized, who had isolated the chain of amino acids restricted with Kir 6.1 and Kir 6.2 proteins from mitochondria.

\section{The Role of ATP-sensitive Potassium Channels in Cellular Defense and CVS protection}

Two self-decision explore offices can put forth a defense possessing first portrayed the ATP-fragile potassium channels [31]. Some report viewed the nearness of an outside current of $\mathrm{K}^{+}$ions in heart muscle cells when treated with hypoxia or metabolic dangerous substances [32]. It was turned around by ATP imbued into the cell. For all intents and purposes indistinguishable recognitions were made by another social event [33]. Such coordinates were next delineated in pancreatic beta cells, skeletal muscle [34], smooth muscle [35] and neurons. It has clarified that the channel showed electrophysiological properties and pharmacological actions [36]. In back to front fixes in $\sim 140 \mathrm{mM}$ balanced $\mathrm{K}^{+}$obsessions, conductance of single-channel is represented ohm ${ }^{-1}$ among a conductance of 70-80 pS. The lower regards now and again observed in composition has lower and upside down $\mathrm{K}^{+}$obsessions. The subdue channel development are produced less by other adenine nucleotides without magnesium because they are ground-breaking. On the other hand, $\mathrm{Mg}^{2+}$, ATP and ADP are considered to produce stimulatory action. Undoubtedly, it was established that channels were known to have a rich pharmacology [37].

Surprisingly, sulphonylureas were discovered when it was wellknown that antimicrobial sulphonamides were also have ability to cause hypoglycaemia and observed in animal models. It was clearly ended up that insulin release induced through beta cells of pancreas due to constraint of KATP channels. As observed in case first age administrator (e.g., tolbutamide, chlorpropamide) and second-age administrators (e.g., glibenclamide, gliclazide, glipizide) which are used in the treatment of diabetes mellitus which opens $\mathrm{K}_{\text {ATP }}$ channels. Furthermore, these administrators particular for $\mathrm{K}_{\text {ATP }}$ channels show extent of substance structures like diazoxide is a benzothiadiazine, pinacidil a cyanoguanidine and nicorandil a pyridyl nitrate [38].

\section{Characteristic Role of the Mitochondrial ATP-sensitive $\mathrm{K}^{+}$Channel in Cardiac Functioning}

Mitochondria are recognized in both bioenergetics and protection in heart against ischemia-reperfusion injury. A broad hypothesis is that the functioning of cardioprotectiion uses the physiological components of mitoK ${ }_{\text {ATP }}$ channel. This work shows that the opening of mitoK $\mathrm{ATP}_{\text {C }}$ channels has 2 special outcomes for heart which depend upon major bioenergetic process when opening of channel occurs. At the point, when DW is high, as in case of opening of mito $\mathrm{K}_{\text {ATP }}$ channels in resting conditions, extended mitochondrial ROS creation and ROS constitutes kinases inside a positive banner expansion circle provoking quality interpretation and cell improvement.

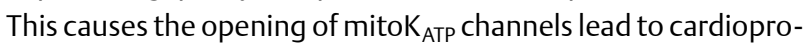
tection against ischemia- reperfusion damage. When, the reduction of DW occurred in ischemia which cause opening of mitoK $\mathrm{K}_{\text {ATP }}$ channel leads to homeostasis. Other $\mathrm{K}^{+}$flow through mitoK $\mathrm{K}_{\text {ATP }}$ channel lowers fundamental force which is basic for keeping a significant transport of electrons and a low conductance of film VDAC. These results assure improvement the midest of work state as well as reperfusion after ischemia [39].

\section{Mechanism of MitoK ${ }_{\text {ATP }}$ Channel Opening through Signaling Pathways of IPC and CPC}

Cardioprotective effects through IPC and CPC is distressed by mitoK $\mathrm{ATP}_{\mathrm{P}}$ inhibitors for example, 5-HD and Glibenclamide. This shows not only that mito $\mathrm{K}_{\mathrm{ATP}}$ is stressed in these techniques for protection, except for those mito $\mathrm{K}_{\text {ATP }}$ channel is opened by endogenous mechanisms [40].

Principally, the cell hyperpolarization occurred in vascular smooth muscle (VSM) is responsible for the opening of $\mathrm{K}_{\text {ATP }}$ channels [41]. A quick phosphorylation of channel subunits KIR6.1|SUR2B (like T633, S1387 and S1465 on SUR2B; S385 on KIR6.1) was observed directly by dynamic sub-nuclear examinations [42]. Additional control may occur through dephosphorylation of these developments for the $\mathrm{Ca}^{2+}$ subordinate phosphatase calcineurin [43]. Vasoconstrictors like angiotensin II and endothelin-1, activation of PKC which adjust $\mathrm{K}_{\text {ATP }}$ channel activity through such pathways [44]. The $\mathrm{Ca}^{2+}$ programmed through PKC $\varepsilon$ mediation organizes phosphorylation of KIR6.1 channel which is responsible for gathering of serine developments in distal C-end as main part. There may be outcomes for channel camouflage and reusing possibly by methods for caveolae [45]. The vasoconstrictors interact with PKA results extra inhibitory assurance to $\mathrm{K}_{\text {ATP }}$ channels [46].

One technique that has been little researched is the piece of PIP2 utilization despite PKC initiation. In some cases, it was found that the control is abolished by PKC inhibitors. KIR6.1 channel seems to have a courteously high activity for PIP2 and channel action may be kept with huge utilization. It was proposed that PKC-asssisted VSM $K_{\text {ATP }}$ activity is subject to produce small movement of vasoconstrictors. The vascular $\mathrm{K}_{\text {ATP }}$ channel and cloned KIR6.1|SUR2B equivalents are focused on hormonal control through direct phosphorylation of subunits. The PKC change has been included as central role in cell protection as well as preconditioning in cardiac cells [47]. In early examinations, PKC was thought to start sarcolemmal cardiovascular $\mathrm{K}_{\text {ATP }}$ and there is a biphasic lead with order took after by an inhibitory action contrasting with channel camouflage [48].

In any case, with unrivaled pipette $\mathrm{Ca}^{2+}$ in whole cell annals in flawless cells and we saw biphasic control. Inhibitory effect was a direct result of channel mask and happened due to phosphorylation of S372 in KIR6.2 protein [49]. The course of sarcolemmal $\mathrm{K}_{\text {ATP }}$ channels through PKA has been inspected. PKA with KIR6.2।SUR1, phosphorylation prompts increased direct development through stores in SUR1 and KIR6.2 that are homologous to those in SUR2B and KIR6.1. One charming component is the subcellular control of $\mathrm{K}_{\text {ATP }}$ channels which radiate an impression of being gathered at the fore-end of T-tubule, putting forward commencement could affect excitation pressure coupling [50].

Mitochondria are a quantitatively significant wellspring of ROS, which supply to tissue harm amid ischemia, but on the other hand are middle people of IPC flagging [51]. Gathering affirmation recommends that redox flagging pathways assume an essential part in IPC $[60,61]$, and ready to advance $\mathrm{mK}_{\text {ATP }}$ actuation [52]. The es- 
sential ROS created by means of mitochondria is superoxide $(\mathrm{O} 2 \bullet-)$ [53], even as hydrogen peroxide $(\mathrm{H} 2 \mathrm{O} 2)$ or lipid peroxides can be shaped optionally. Both $\mathrm{O} 2 \cdot-$ and $\mathrm{H} 2 \mathrm{O} 2$ are thought to actuate $\mathrm{mK}_{\text {ATP }}$ [54], while clashing reports exist with respect to $\mathrm{O} 2$. The impact of extra peroxides on $\mathrm{mK}_{\text {ATP }}$ isn't known. In addition, it is evident that a few yet not a wide range of cancer prevention agents can lessen IPC and $\mathrm{mK}_{\text {ATP }}$ action, justifying more examination $\mathrm{mK}_{\text {ATP }}$ channel. Nitric oxide $(\mathrm{NO} \bullet$ ) is additionally worried in IPC and inspires a major range of cardioprotective effects [55]. NO• have been recognized in the separated mitochondrial courses of action [56] and can alternatively provide various responsive nitrogen species [57] which can provide either harmful or supportive fading parts [58].

The mKATP may be a likely center for such RNS, and whereas while high doses $(10 \mathrm{mM})$ of a S-nitroso-thiol (SNT) have been displayed to activate directly in the faultless mitochondria and affirmation for more physiologically pertinent effects of NO • has observed for the foremost portion depended on the circuitous measures of channel moveement [59] or examination of the channel ousted from its mitochondrial condition [60].

\section{Biophysical Characteristics of $\mathrm{K}_{\text {ATP }}$ Channels in Managing Vascular Diseases}

Potassium channels vascular infections changed vascular potassium channel work beneath neurotic conditions may well be either a reason or an affect of contamination. Vasoconstriction and course of action that of a vein limit to broaden are after effects of damaged $K_{1}$ channels restrain in veins and may be direct result of an al- teration in number, basic conductance, and open validity of the channel(s).

All together at this level with respect to $K_{1}$ channel articulation can starting at now be given just by ponders atomic and also settle prop approaches and thusly, are limited to examinations of veins or cardio-myocytes are abolished from the physiological condition [61]. In this manner, where probability permits (i. e., the accessibility of specific pharmacological instruments), it will stay basic to check such revelations with data about vascular $\mathrm{K}_{1}$ coordinate limit procured in the joined physiological condition in vivo ( $\triangleright$ Fig. 1).

Particularly few circulated examinations have been broken down impact of infection on biophysical features of $\mathrm{K}_{1}$ channels or subunits. As shown above, the greater piece of our understanding into affect of illnesses on vascular $\mathrm{K}_{1}$ channel articulation remains underhanded and subject to clarification of the test information attained by utilizing $\mathrm{K}_{1}$ channel modulators that are accepted to be modestly particular pharmacological specialists [62].

\section{Contribution of $\mathrm{K}_{\text {ATP }}$ Channels in Cerebro- Vascular Hypertension}

The persistent hypertension is the most frequent thought about cardiovascular infectivity state similarly as its effects on vascular $\mathrm{K}_{1}$ channel exertion. At present, there is unpredictable working of each one of the 4 vital $K_{1}$ channels makes in midst of Effects out of Hypertension on electrical membrane (Em). The resting Em of vascular smooth muscle cells is represented to be more depolarized in veins from hypertensive versus normotensive animals. Extended

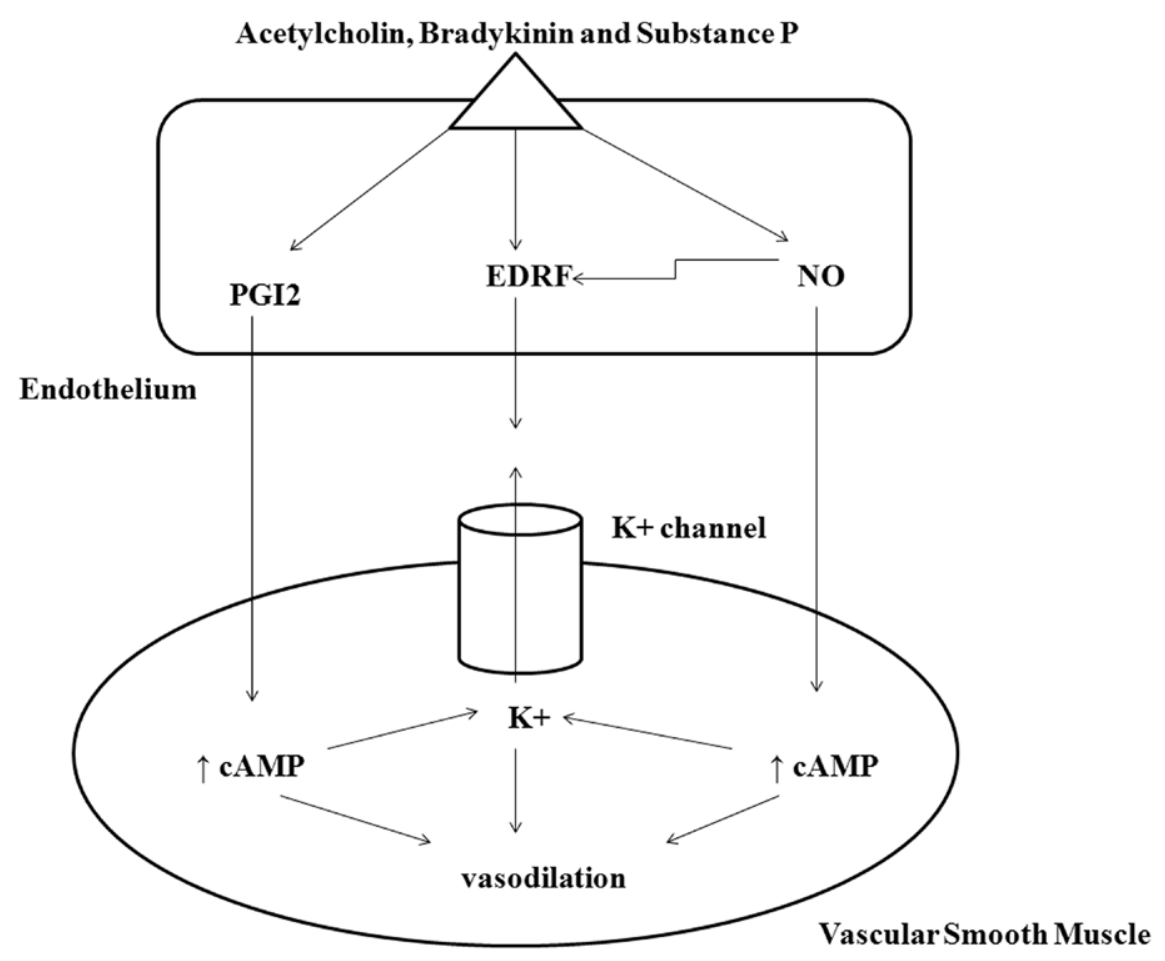

-Fig. 1 Some potential instruments including $\mathrm{K}_{1}$ channel-mediated, endothelium-subordinate hyperpolarization and involvement of various mediators. 
vascular depolarization of vessels is related with overhauled myogenic tone in halls from hypertensive animals [63].

Few examinations propose that the restrain of vascular $\mathrm{K}_{\text {ATP }}$ channels is prevented within the middle of hypertension. Existing $\mathrm{K}_{\mathrm{ATP}}$ channel activators are less sensible dilators invivo in both enormous [64] and small cerebral vessels of persistently hypertensive rats [65]. This alteration shows up to most likely consolidate a weakened layer hyperpolarization response to these administrators, as essentially indistinguish-able disclosures from settle catch contemplates demonstrate that a glibenclamide-unstable $\mathrm{K}_{1}$ current started by levcromakalim is reduced in mesenteric entry in smooth muscle cells of tenaciously hypertensive animals [66]. Cromakalim provoked extricating up of isolated mesenteric course is unclear prevented in case of hypertension initiated by unending NO synthase prevention [67].

The vascular $\mathrm{K}_{\text {ATP }}$ channels are accepted to be inactive under most normal basal conditions and amplified vascular tone within the middle of perpetual hypertension is improbable to be related to disabled $\mathrm{K}_{\text {ATP }}$ channel effort. For improved $\mathrm{K}_{\text {ATP }}$ channel effort, in continual hypertension, an extended vasodilator effect of cromakalim and significant choking of channel by glibenclamide in carotid ways from stroke-slanted SHRs against normotensive WKY rats has been considered [68].

\section{$\mathrm{K}_{\text {ATP }}$ Channels in Diabetes and Resulting to Hypertension in Vascular Bed}

Most of information right now open for vascular $\mathrm{K}_{1}$ occupies exertion in diabetes involving $\mathrm{K}_{\text {ATP }}$ channels. While for never-ending hypertension, different reports of debilitated vascular relaxant properties produced to open $\mathrm{K}_{\text {ATP }}$ channels which deal diabetes.

These examinations have for the mosly exploited the streptozotocin induced rat model of diabetes and have explored vessels at 2.5-4 months coming approximately to treatment with streptozotocin. In this method, the plasma glucose level are increased by 3 to 4-times; debilitated extricating up of the segregated aorta [69] and mesenteric vascular bed [70] and decreased dilatation of far reaching [71] and little [72] cerebral passages in vivo. These developments are accepted to be the possible result leads decrease in number of $\mathrm{K}_{\text {ATP }}$ channels and moreover decreased affectability of said channels design openers. Redirection of streptozotocin induced cytotoxic effects of show up a fantastical purpose behind these movements in light of the way that, as various indications of vascular brokenness, flighty vasodilator actions through $\mathrm{K}_{\text {ATP }}$ channel opening are neutralized by prescriptions that keep away from hyperglycemia.

Streptozotocin aggravated diabetes can essentially alter utilitarian response of $\mathrm{K}_{\text {ATP }}$ facilitates in different tissues, with pancreatic beta-cells [73] and ventricular myocytes, [74] showing that hyperglycemia started debilitation of $\mathrm{K}_{\text {ATP }}$ channels is not compelled to vasculature. Since, diabetes is characterized with raised levels of cholesterol, LDL and triglycerides in plasma. It is conceivable that some vascular difficulties of diabetes are not directly linked to hyperglycemia which is a resultant of balanced plasma lipid profile [75].

Period of exploratory hyperglycemia has each one of the saves of being indispensable parameters observed impacts of diabetes on vascular $\mathrm{K}_{\text {ATP }}$ channel work in light of the way that that by disparity, reactions to $K_{\text {ATP }}$ channel institution are represented to be dominating in the early diabetic state ( $\vee$ Fig. 2). For illustration, cromakalim actuated dilatation of colossal coronary supply courses in pooch are extended multi week behind treatment with alloxan, and responses of the small coronary paths are unaffected [76]. Additionally, glibenclamide produce stamped narrowing of vessels. The extended articulation and basal order of $\mathrm{K}_{\text {ATP }}$ channels occur together in the renal stream in front of schedule in midst of diabetes [77].

This condition can include to the upgrades in glomerular filtration rate and renal plasma stream, which develop in in beginning times of diabetes in both clinical and test settings [78]. An expanded $\mathrm{K}_{\text {ATP }}$ channel activity right directly may along these lines reflect a elevated metabolic state (i. e., low ATP levels) of smooth muscle cells not long after the starting of hyperglycemia. Extended $\mathrm{K}_{\text {ATP }}$ arrange activity in veins through metabolic weight, for occasion, within the middle of ischemia, may important for keeping up tissue perfusion.

In this way, tissues may well be additional powerless to the ischemic heart after expanded circumstances of diabetes inferable from debilitated limit of $\mathrm{K}_{\text {ATP }}$ channels. On the other hand, differentiated impacts on $\mathrm{K}_{\text {ATP }}$ channel work are represented to occur 2 months after after affirmation of hyperglycemia, most likely to a limited degree reflecting a ceaseless drop of vascular systems the middle of improvement of disease.

Since, Bouchard et al. reported that vasorelaxant response to lemakalim is weakend in coronary vessels, not in the vascular bed following 2 months of hyperglycemia. Pinacidil-started hyper-polarization of the mesenteric vein was represented to be protected consequent to 8 to 12 weeks. Zimmerman et al. [79] revealed that dilator activities leads to $\mathrm{K}_{\text {ATP }}$ opening were obstructed in cerebral courses from 4 to 8 -week-diabetic rats coming about from lessened basal complimentary of endothelium-induced NO. The $\mathrm{K}_{\text {ATP }}$ channels restrain was re-established in diabetic vessels associated with consistent NO support [80].

Of course, such an instrument of endothelial NO-subordinate $\mathrm{K}_{\text {ATP }}$ channel activation couldn't occur in different stages, as no certification of an area was found for NO dilator activities in rodent cerebral vessels through $\mathrm{K}_{\text {ATP }}$ channel opening [81].

\section{Hypercholesterolemia, Atherosclerosis, Cardiomyocyte Swelling and Heart Failure}

It is particularly seen that vascular blocking occurred in atherosclerosis and hypercholesterolemia. Such contamination is associated with handicap of endothelial limit. The diminished vascular enlargement of endothelium-affected NO is presumably going to participate a vital part in change of atherosclerosis [82]. As a result, supply courses may exhibit an extended vascular tone and may react deficiently to endothelium-subordinate vasodilators. Under such condition of changed vascular reactivity, $\mathrm{K}_{1}$ channel development or limit may similarly be unordinary [83].

The hypertrophy of heart is enacted by an expanded in addition to cardiovascular workload. While, transverse aortic fixing was apply in mice with heart specific over expression of SUR1 which limitlessly disturbs cardiovascular sarcolemmal $\mathrm{K}_{\text {ATP }}$ channel utility, extended hypertrophy of left ventricle was viewed [84]. Inquisitively, there is 


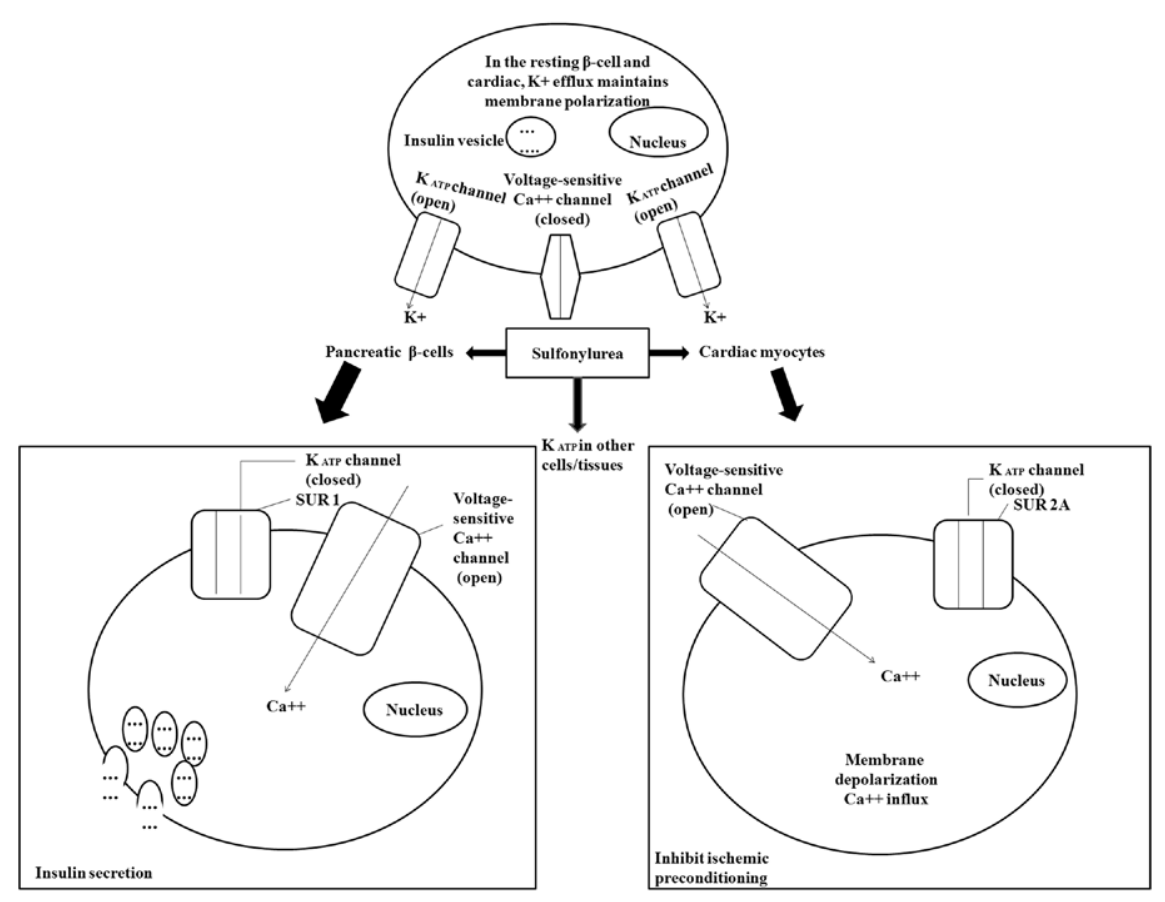

Fig. 2 Schematic depiction of the affect of SUs on pancreatic $\beta$-cells and cardiovascular myocytes. Sulfonylureas tie to sulfonylurea receptor proteins (SURs), subunits of the KATP channels.

in every way a correspondence between cardiovascular $\mathrm{K}_{\text {ATP }}$ channel enunciation and the action of the PPAR-y co-activator, PGC- $1 \alpha$. Reduced channel reason prompts less activity at PGC- $1 \alpha$ promoter to some degree through FOXO-1 concealment. Restored ventricular cardiomyocytes are subjected to coronary hindrance in rats show up control of KIR6.1, in the demand of the infarct zone [85]. Congestive heart dissatisfaction or restricted corruption in human hearts prompts an upgraded AP term and affectability to potassium channel openers in the 2 atria and ventricles [86].

Angiotensin II and TNF- $\alpha$ enunciation is insistently related to that of KIR6. 1 in failing rat myocardium or created cardiomyocytes and antagonistically related with KIR6.2 [87]. Moreover, cardiomyocytes were treated with diazoxide, exhibiting extended enunciation of KIR6.1/SUR2B in these cells as a noteworthy part of hypertrophy development. Over the best changes in cell volume in the heart item would have capacity to alter the essential cell credibility, cell limits and cell destruction. These movements can raise because of an intracellular metabolite sign that extension cell osmolality, empower water to enter the cell, augment the cell volume and alter molecule channel work. $\mathrm{K}_{\text {ATP }}$ channel chas been seemed to occur in cellular changes with atrial $\mathrm{K}_{\mathrm{ATP}}$ coordinates opening in view of cell swelling provocating AP shortening [88]. The non-attendance of KIR6.2 in cardiovascular myocytes led to cell swelling while in WT mice cell swelling exaggerated which is bothered by extension of diazoxide [89].

\section{Cardioprotective Effect of Ischemic Preconditioning in Ovariectomized Rat Heart}

The affirmation of caveolin,, a membrane protein and and a unsafe controller of nitric oxide (NO), saises after menopause Examination was anticipated to choose the impact of daidzein (DDZ), a phytoestrogen is included to appear cardioprotective effect of ischemic preconditioning (IPC) in ovariectomized rat heart.

IPC helped cardioprotection was broadly fixed in ovariectomized rats when stood out from run of the process rats, which recovered, was reestablished by the treatment of DDZ, a caveolin inhibitor $(0.2 \mathrm{mg} / \mathrm{kg}$ subcutaneously) for for numerous weeks. In any case, this observed cardioprotection was amazingly diminished by perfusion of L-nitroarginine methyl ester, an endothelial nitric oxide synthase (eNOS) inhibitor ( $100 \mathrm{mM} / \mathrm{L}$ ) and glibenclamide, an adenosine triphosphate-fragile potassium channel blocker ( $10 \mathrm{mM} / \mathrm{L})$ alone or in mix, noted that expansion in myocardial infarct assess, landing of $\mathrm{LDH}$ and CK-MB, and and other than diminish within the section of NO.

Opening of mitochondrial $\mathrm{K}_{\text {ATP }}$ channels shields the myocardium from I/R-affected damage [90]. Different mediators like adenosine, bradykinin, angiotensin, prostaglandins and NO, which are increased in IPC, pass on cardioprotection by the opening of mitochondrial $K_{\text {ATP }}$ channel [91, 92]. Further, perfusion of glibenclamide, a $\mathrm{K}_{\text {ATP }}$ involve blocker in DDZ-pretreated ovariectomized rat heart in a general sense, dropped the cardioprotective effect of IPC without influencing the IPC-intervened entry of NO. 
It is discretionary that the watched cardioprotective impact of IPC in rodent and DDZ-pretreated rodent may be may be a coordinate result of opening of mitochondrial $\mathrm{K}_{\text {ATP }}$ channel. Also, perfusion of L-NAME with Glibenclamide in DDZ-pretreated ovariectomized rodent heart was not capable to create any extra effect in examination with specific drugs. These revelations reflect that NO conveyed in light of IPC in DDZ-pretreated ovariectomized rodent heart make cardioprotection by the opening of $\mathrm{K}_{\text {ATP }}$ channels [93].

\section{Conclusion}

In summary, we have demonstrated the role of the potassium channel in mediating delayed ischemic preconditioning. It is confirmed that blockers were acting at potassium channel. Further studies will be necessary to unravel the specific signal transduction mechanism by which delayed preconditioning leads to the opening of these channels and differentiating the specific role played by each of the sarcolemmal and mitochondrial potassium channels in mediating delayed cardio protective effect in vivo.

\section{Clinical Implications}

It has been indicated from various disorders that mitochondrial ATP sensitive potassium channels are critical which trigger IPC as opposed to sarcolemmal potassium channels. The increment in potassium channel mediations decides metabolic changes and energy required within the dissipation.

These channels can be determined with a role in pharmacological and biophysical properties. Nevertheless, the importance of the potassium channels reconsidered in cardio-protection in present findings. The usefulness of such studies indicates a fundamental role of potassium channels in a variety of CVS disorders including arrthymias, hypertension and heart failures.

These findings suggest that potassium channels within the adjusting ischemic-reperfusion injury in mice. The heart rate of the mouse occurred during ischemia and probably enhances vigilant extrapolation applied to larger warm blooded animals.

\section{Limitations of Study}

A study of mechanistic pathways mediating potassium channels provides the knowledge of cell functions and cardio protection and limits to cardiovascular functions and pathways. ATP sensitive potassium channels adjust excitability of membrane and control metabolic functions. Limitations of this study include missing of experimental protocols with justification and involvement of potassium channels. A lot of advancements in this field those are not proved till date which are not included. A lack of wide versatility of potassium channels in the study for physiological functions.

\section{Acknowledgements}

We are grateful to Prof Pradeep Mishra, Director, Institute of Pharmaceutical Research, GLA University, Mathura (U.P.) and Prof Anup Matri, Principal, Rajarshi Rananjay Sinh college of Pharmacy, Amethi, (U.P.) for providing e-resources and library facilities for this study.

\section{Conflict of Interest}

Authors did not have any conflict of interest in writing and publishing the manuscript.

\section{References}

[1] De Wet H, Proks P. Molecular action of sulphonylureas on KATP channels: A real partnership between drugs and nucleotides. Biochem Soc Trans 2015; 43: 901-907

[2] Maclntosh BR, Holash RJ, Renaud JM. Skeletal muscle fatigue-regulation of excitation-contraction coupling to avoid metabolic catastrophe. J Cell Sci 2012; 125: 2105-2114

[3] Flagg TP, Enkvetchakul D, Koster JC et al. Muscle KATP channels: Recent insights to energy sensing and myoprotection. Physiol Rev 2010; 90: 799-829

[4] Nichols CG. Adenosine triphosphate-sensitive potassium currents in heart disease and cardioprotection. Card Electrophysiol Clin 2016; 8: 323-335

[5] Gok S, Vural K, Sekuri C et al. Effects of the blockade of cardiac sarcolemmal ATP-sensitive potassium channels on arrhythmias and coronary flow in ischemia-reperfusion model in isolated rat hearts. Vascul Pharmacol. 2006; 44: 197-205

[6] Alekseev AE, Reyes S, Yamada S et al. Sarcolemmal ATP-sensitive K(+) channels control energy expenditure determining body weight. Cell Metab. 2010; 11: 58-69

[7] Garrott K, Kuzmiak-Glancy S, Wengrowski A et al. K ATP channel inhibition blunts electromechanical decline during hypoxia in left ventricular working rabbit hearts. J Physiol. 2017; 595: 3799-3813

[8] Murry CE, Jennings RB, Reimer KA. Preconditioning with ischemia: A delay of lethal cell injury in ischemic myocardium. Circulation. 1986; 74: 1124-1136

[9] Blondeau N, Plamondon H, Richelme C et al. K(ATP) channel openers, adenosine agonists and epileptic preconditioning are stress signals inducing hippocampal neuroprotection. Neuroscience. 2000; 100 : 465-474

[10] Grover G], D’Alonzo AJ, Parham CS et al. Cardioprotection with the KATP opener cromakalim is not correlated with ischemic myocardial action potential duration. J Cardiovasc Pharmacol 1995; 26: 145-152

[11] Schultz JE, Kwok WM, Hsu AK et al. Terikalant, an inward-rectifier potassium channel blocker, does not abolish the cardioprotection induced by ischemic preconditioning in the rat. J Mol Cell Cardiol 1998; 30: 1817-1825

[12] Sato T, Sasaki N, Seharaseyon J et al. Selective pharmacological agents implicate mitochondrial but not sarcolemmal KATP channels in ischemic cardioprotection. Circulation. 2000; 101: 2418-2423

[13] Jovanovic S, Jovanovic A. Delivery of genes encoding cardiac K(ATP) channel subunits in conjunction with pinacidil prevents membrane depolarization in cells exposed to chemical hypoxia-reoxygenation. Biochem Biophys Res Commun 2001; 282: 1098-1102

[14] Er F, Michels G, Gassanov N et al. Testosterone induces cytoprotection by activating ATP-sensitive $\mathrm{K}+$ channels in the cardiac mitochondrial inner membrane. Circulation. 2004; 110: 3100-3107

[15] Ohtsuka T, Ishiwa D, Kamiya Y et al. Effects of barbiturates on ATP-sensitive $K$ channels in rat substantia nigra. Neuroscience. 2006; 137: 573-581

[16] Gong B, Miki T, Seino S et al. A KATP channel deficiency affects resting tension, not contractile force, during fatigue in skeletal muscle. Am J Physiol 2000; 279: C1351-C1358

[17] Chen X, Minatoguchi S, Wang N et al. Quinaprilat reduces myocardial infarct size involving nitric oxide production and mitochondrial KATPchannel in rabbits. J Cardiovasc Pharmacol 2003; 41: 938-945 
[18] Ghosh S, Standen NB, Galiñanes M. Evidence for mitochondrial KATP channels as effectors of human myocardial preconditioning. Cardiovasc. Res 2000; 45: 934-940

[19] Gross G], Fryer RM. Sarcolemmal versus mitochondrial ATPsensitive $\mathrm{K}+$ channels and myocardial preconditioning. Circ Res. 1999; 84: 973-979

[20] Das B, Sarkar C. Similarities between ischemic preconditioning and 17beta-estradiol mediated cardiomyocyte KATPchannel activation leading to cardioprotective and antiarrhythmic effects during ischemia/reperfusion in the intact rabbit heart. J Cardiovasc Pharmacol 2006; 47: 277-286

[21] Das B, Sarkar C. Is the sarcolemmal or mitochondrial K(ATP) channel activation important in the antiarrhythmic and cardioprotective effects during acute ischemia/reperfusion in the intact anesthetized rabbit model? Life Sci. 2005; 77: 1226-1248

[22] Toller WG, Gross ER, Kersten JR et al. Sarcolemmal and mitochondrial adenosine triphosphate-dependent potassium channels: Mechanism of desfluraneinduced cardioprotection. Anesthesiology. 2000; 92: $1731-1739$

[23] Bever L, Poitry S, Faure C et al. Pore loop-mutated rat KIR6.1 and KIR6.2 suppress KATP current in rat cardiomyocytes. Am J Physiol Heart Circ Physiol 2004; 287: H850-H859

[24] Miura H, Wachtel RE, Loberiza FR Jr. et al. Diabetes mellitus impairs vasodilation to hypoxia in human coronary arterioles: Reduced activity of ATP-sensitive potassium channels. Circ Res. 2003; 92: 151-158

[25] Singh H, Hudman D, Lawrence CL et al. Distribution of Kir6.0 and SUR2 ATP-sensitive potassium channel subunits in isolated ventricular myocytes. J Mol Cell Cardiol 2003; 35: 445-459

[26] Zhou M, Tanaka O, Suzuki M et al. Localization of pore-forming subunit of the ATP-sensitive K()-channel, Kir6.2, in rat brain neurons and glial cells. Brain Res Mol Brain Res 2002; 101: 23-32

[27] Teramoto N. Pharmacological profile of U-37883A, a channel blocker of smooth muscle-type ATP-sensitive K channels. Cardiovasc Drug Rev 2006; 24: 25-32

[28] Seharaseyon J, Ohler A, Sasaki $\mathrm{N}$ et al. Molecular composition of mitochondrial ATP-sensitive potassium channels probed by viral Kir gene transfer. J Mol Cell Cardiol 2000; 32: 1923-1930

[29] Kuniyasu A, Kaneko K, Kawahara K et al. Molecular assembly and subcellular distribution of ATP-sensitive potassium channel proteins in rat hearts. FEBS Lett 2003; 552: 259-263

[30] Lacza Z, Snipes JA, Miller AW et al. Heart mitochondria contain functional ATP-dependent K channels. J Mol Cell Cardiol 2003; 35 : 1339-1347

[31] Alexander SP, Benson HE, Faccenda E et al. The concise guide to pharmacology 2013/14: Overview. Br J Pharmacol 2013; 170 : 1449-1867

[32] Oketani N, Kakei M, Ichinari K et al. Regulation of K(ATP) channels by $\mathrm{P}(2 \mathrm{Y})$ purinoceptors coupled to PIP(2) metabolism in guinea pig ventricular cells. Am J Physiol Heart Circ Physiol 2002; 282: H757H765

[33] Trube G, Hescheler J. Inward-rectifying channels in isolated patches of the heart cell membrane: ATP-dependence and comparison with cell-attached patches. Pflugers Arch 1984; 401: 178-184

[34] Spruce AE, Standen NB, Stanfield PR. Voltage-dependent ATP-sensitive potassium channels of skeletal muscle membrane. Nature. 1985; 316 : 736-738

[35] Standen NB, Quayle JM, Davies NW et al. Hyperpolarizing vasodilators activate ATP-sensitive $\mathrm{K}+$ channels in arterial smooth muscle. Science. 1989; 245: 177-180

[36] Noma A, Takano M. The ATP-sensitive K + channel. Jpn J Physiol 1991; 41: $177-187$
[37] Wakeno-Takahashi M, Otani $\mathrm{H}$, Nakao S et al. Adenosine and a nitric oxide donor enhances cardioprotection by preconditioning with isoflurane through mitochondrial adenosine triphosphate-sensitive $\mathrm{K}+$ channel-dependent and -independent mechanisms. Anesthesiology. 2004; 100: 515-524

[38] Mannhold R. Structure-activity relationships of K(ATP) channel openers. Curr Top Med Chem 2006; 6: 1031-1047

[39] Saks V, Kaambre T, Guzun R et al. The creatine kinase phosphotransfer network: Thermodynamic and kinetic considerations, the impact of the mitochondrial outer membrane and modelling approaches. Subcell Biochem 2007; 46: 27-65

[40] Garlid KD, Paucek P. Mitochondrial potassium transport: The K+ cycle Biochim Biophys Acta. 2003; 1606: 23-41

[41] Rodrigo GC, Standen NB. ATP-sensitive potassium channels. Curr Pharm Des 2005; 11: 1915-1940

[42] Shi Y, Wu Z, Cui N et al. PKA phosphorylation of SUR2B subunit underscores vascular KATP channel activation by beta-adrenergic receptors. Am J Physiol Regul Integr Comp Physiol 2007; 293: R1205-R1214

[43] Orie NN, Thomas AM, Perrino BA et al. Ca2 + /calcineurin regulation of cloned vascular K ATP channels: Crosstalk with the protein kinase A pathway. Br J Pharmacol 2009; 157: 554-564

[44] Sampson LJ, Davies LM, Barrett-Jolley R et al. Angiotensin II-activated protein kinase $C$ targets caveolae to inhibit aortic ATP-sensitive potassium channels. Cardiovasc Res. 2007; 76: 61-70

[45] Jiao J, Garg V, Yang B et al. Protein kinase C-epsilon induces caveolindependent internalization of vascular adenosine 5 '-triphosphatesensitive K + channels. Hypertension. 2008; 52: 499-506

[46] Hayabuchi Y, Davies NW, Standen NB.(2001b) Angiotensin II inhibits rat arterial KATP channels by inhibiting steady-state protein kinase A activity and activating protein kinase Ce. J Physiol 2001; 530: 193-205

[47] Yellon DM, Downey JM. Preconditioning the myocardium: From cellular physiology to clinical cardiology. Physiol Rev. 2003; 83: 1113-1151

[48] Light PE, Sabir AA, Allen BG et al. Protein kinase C-induced changes in the stoichiometry of ATP binding activate cardiac ATP-sensitive $\mathrm{K}+$ channels. A possible mechanistic link to ischemic preconditioning. Circ Res. 1996; 79: 399-406

[49] Aziz Q, Thomas AM, Khambra T et al. Regulation of the ATP-sensitive potassium channel subunit, Kir6.2, by a Ca2 +-dependent protein kinase C. J Biol Chem 2012; 287: 6196-6207

[50] Korchev YE, Negulyaev YA, Edwards CR et al. Functional localization of single active ion channels on the surface of a living cell. Nat Cell Biol 2000; 2: 616-619

[51] Murphy E, Steenbergen C. Preconditioning: The mitochondrial connection. Annu Rev Physiol 2007; 69: 51-67

[52] Forbes RA, Steenbergen C, Murphy E. Diazoxide-induced cardioprotection requires signaling through a redox-sensitive mechanism. Circ Res. 2001; 88: 802-809

[53] Murphy MP. How mitochondria produce reactive oxygen species. Biochem J. 2009; 417: 1-13

[54] Fornazari M, De Paula JG, Castilho RF et al. Redox properties of the adenoside triphosphate-sensitive $\mathrm{K}+$ channel in brain mitochondria. J Neurosci Res 2008; 86: 1548-1556

[55] Burwell LS, Brookes PS. Mitochondria asatarget for the cardioprotective effects of nitric oxide in ischemia-reperfusion injury. Antioxid Redox Signal 2007; 10: 579-600

[56] Giulivi C, Poderoso J], Boveris A. Production of nitric oxide by mitochondria. J Biol Chem 1998; 273: 11038-11043

[57] Rudolph V, Freeman BA. Cardiovascular consequences when nitric oxide and lipid signaling converge. Circ Res. 2009; 105: 511-522 
[58] Sasaki N, Sato T, Ohler A et al. Activation of mitochondrial ATP-dependent potassium channels by nitric oxide. Circulation. 2000; 101: 439-445

[59] Ljubkovic M, Shi Y, Cheng Q et al. Cardiac mitochondrial ATPsensitive potassium channel is activated by nitric oxide in vitro. FEBS Lett 2007; 581: 4255-4259

[60] Nelson MT, Quayle JM. Physiological roles and properties of potassium channels in arterial smooth muscle. Am J Physiol 1995; 268: C799-C822

[61] Faraci FM, Heistad DD. Regulation of the cerebral circulation: Role of endothelium and potassium channels. Physiol Rev. 1998; 78: 53-97

[62] Harder DR, Smeda J, Lombard J. Enhanced myogenic depolarization in hypertensive cerebral arterial muscle. Circ Res. 1985; 57: 319-322

[63] Kitazono T, Heistad DD, Faraci FM. ATP-sensitive potassium channels in the basilar artery during chronic hypertension. Hypertension. 1993; 22: 677-681

[64] Sobey CG, Heistad DD, Faraci FM. Effect of subarachnoid hemorrhage on cerebral vasodilatation in response to activation of ATP-sensitive K1 channels in chronically hypertensive rats. Stroke. 1997; 28: 392-397

[65] Ohya Y, Setoguchi M, Fujii K et al. Impaired action of levcromakalim on ATP-sensitive K1 channels in mesenteric artery cells from spontaneously hypertensive rats. Hypertension. 1996; 27: 1234-1239

[66] Kalliovalkama J, Jolma P, Tolvanen J-P et al. Arterial function in nitric oxide-deficient hypertension: Influence of long-term angiotensin II receptor antagonism. Cardiovasc Res 1999; 42: 773-782

[67] Miyata N, Tsuschida K, Otomo S. Functional changes in potassium channels in carotid arteries from stroke-prone spontaneously hypertensive rats. Eur J Pharmacol 1990; 182: 209-210

[68] Kamata K, Miyata N, Kasuya Y. Functional changes in potassium channels in aortas from rats with streptozotocin-induced diabetes. Eur J Pharmacol 1989; 166: 319-323

[69] Bouchard J-F, Dumont EC, Lamontagne D. Modification of vasodilator response in streptozotocin-induced diabetic rat. Can J Physiol Pharmacol 1999; 77: 980-985

[70] Mayhan WG. Effect of diabetes mellitus on response of the basilar artery to activation of ATP-sensitive potassium channels. Brain Res. 1994; 636: 35-39

[71] Mayhan WG, Faraci FM. Responses of cerebral arterioles in diabetic rats to activation of ATP-sensitive potassium channels. Am J Physiol 1993; 265: $\mathrm{H} 152-\mathrm{H} 157$

[72] Tsuura Y, Ishida H, Okamoto Y et al. Impaired glucose sensitivity of ATP-sensitive $\mathrm{K} 1$ channels in pancreatic $\mathrm{b}$-cells in streptozotocininduced NIDDM rats. Diabetes. 1992; 41: 861-865

[73] Shimoni Y, Firek L, Severson D et al. Short-term diabetes alters $\mathrm{K} 1$ currents in rat ventricular myocytes. Circ Res. 1994; 74: 620-628

[74] Makino A, Ohuchi K, Kamata K. Mechanisms underlying the attenuation of endothelium-dependent vasodilatation in the mesenteric arterial bed of the streptozotocin-induced diabetic rat. $\mathrm{Br}$ J Pharmacol 2000; 130: 549-556

[75] Kersten JR, Brooks LA, Dellsperger KC. Impaired microvascular response to graded coronary occlusion in diabetic and hyperglycemic dogs. Am J Physiol 1995; 268: H1667-H1674

[76] Ikenaga H, Bast JP, Fallet RW et al. Exaggerated impact of ATP-sensitive $\mathrm{K} 1$ channels on afferent arteriolar diameter in diabetes mellitus. J Am Soc Nephrol 2000; 11: 1199-1207
[77] Hostetter TH, Troy JL, Brenner BM. Glomerular hemodynamics in experimental diabetes mellitus. Kidney Int. 1981; 19: 410-415

[78] Fukao M, Hattori Y, Kanno M et al. Alterations in endothelium-dependent hyperpolarization and relaxation in mesenteric arteries from streptozotocin-induced diabetic rats. Br J Pharmacol 1997; 121: 1383-1391

[79] Zimmerman PA, Knot H], Stevenson AS et al. Increased myogenic tone and diminished responsiveness to ATP-sensitive K1 channel openers in cerebral arteries from diabetic rats. Circ Res. 1997; 81: 996-1004

[80] Sobey CG, Faraci FM. Effect of nitric oxide and potassium channel agonists and inhibitors on basilar artery diameter. Am J Physiol 1997; 272: H256-H262

[81] Faraci FM, Orgren K, Heistad DD. Impaired relaxation of the carotid artery during activation of ATP-sensitive potassium channels in atherosclerotic monkeys. Stroke. 1994; 25: 178-182

[82] Taguchi H, Faraci FM, Kitazono T et al. Relaxation of the carotid artery to hypoxia is impaired in Watanabe Heritable Hyperlipidemic rabbits. Arterioscler Thromb Vasc Biol 1995; 15: 1641-1645

[83] Yamada S, Kane GC, Behfar A et al. Protection conferred by myocardial ATP-sensitive $\mathrm{K}^{+}$channels in pressure overload-induced congestive heart failure revealed in KCNJ11 Kir6.2-null mutant. J Physiol 2006; 577: 1053-1065

[84] Isidoro TN, Philip-Couderc P, Papageorgiou I et al. Expression and function of ATP-dependent potassium channels in late post-infarction remodeling. J Mol Cell Cardiol 2007; 42: 1016-1025

[85] Fedorov VV, Glukhov AV, Ambrosi CM et al. Effects of KATP channel openers diazoxide and pinacidil in coronary-perfused atria and ventricles from failing and non-failing human hearts. J Mol Cell Cardiol 2009; 51: 215-225

[86] Isidoro TN, Philip-Couderc P, Baertschi A] et al. Angiotensin II and tumour necrosis factor alpha as mediators of ATP-dependent potassium channel remodelling in post-infarction heart failure. Cardiovasc Res. 2009; 83: 726-736

[87] Saegusa N, Sato T, Saito T et al. Kir 6.2-deficient mice are susceptible to stimulated ANP secretion: $\mathrm{K}$ (ATP) channel acts as a negative feedback mechanism. Cardiovasc Res. 2005; 67: 60-68

[88] Prasad SM, Al-Dadah AS, Byrd GD et al. Role of the sarcolemmal adenosine triphosphatesensitive potassium channel in hyperkalemic cardioplegia-induced myocyte swelling and reduced contractility. Ann Thorac 2006; 81: 148-153

[89] Taliyan R, Singh M, Sharma PL et al. Possible involvement of $\alpha 1$ adrenergic receptor and KATP channels in cardioprotective effect of remote aortic preconditioning in isolated rat heart. J Cardiovasc Dis Res 2010; 1: 145-151

[90] Baines CP, Cohen MV, Downey JM. Signal transduction in ischemic preconditioning: The role of kinases and mitochondrial KATP channels. | Cardiovasc Electr 1999; 10: 741-754

[91] Murphy E. Primary and secondary signalling pathways in early preconditioning that converge on the mitochondria to produce cardioprotection. Circ Res. 2004; 94: 7-16

[92] Goyal A, Semwal B, Yadav HN. Abrogated cardioprotective ischemic preconditioning in ovariectomized heart. Human \& experimental toxicology 2015; 10: 1-10

[93] Oldenburg O, Cohen MV, Yellon DM et al. Mitochondrial K(ATP) channels: Role in cardioprotection. Cardiovasc Res 2002; 55: 429-437 